FAGUTVIKLING

\title{
Helsepersonell trenger å lære mer om bruk av tvang mot barn
}

\section{Tvang kan forekomme når barn motsetter seg behandling. Dette kan oppleves som svært traumatisk. Innsatsen bør heller settes inn på å forebygge tvang.}

\section{Edel Jannecke Svendsen}

Barnesykepleier

Barn

Pasientrettighet

Sykepleie

Tvang

Videre- ogetterutdanning

Forebygging

Sykepleien 2018;106(71912):e-71912

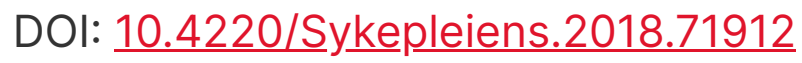

Hovedbudskap

Mange førskolebarn er redde og engstelige for ubehagelige prosedyrer og behandling på sykehus. Eksempler på slike prosedyrer er innleggelse av perifer venekanyle, venepunksjon eller innledning til narkose. Når barn motsetter seg slik behandling kan det ende med at helsepersonell benytter tvang.

De få forekomststudier som finnes viser at tvang forekommer under mange vanlige sykehusprosedyrer (1). Slike situasjoner er komplekse og barn, foreldre og helsepersonell kan ha svært ulik oppfatning av bruk av tvang. For å redusere bruk av tvang kreves det kompetanse om disse forholdene. Hvilke oppfatninger av tvang eksisterer og hvilke implikasjoner har dette for kompetanseutvikling av helsepersonell som har omsorgen for barn i sykehus? 
Innholdet i tvangsbegrepet kan være ulikt alt ettersom hvem som benytter begrepet eller hva som legges i det. Også i de ulike lovene for bruk av tvang i helsevesenet varierer definisjonene. Én definisjon fra lovverket er: «Tvang og makt er definert som tiltak som tjenestemottakeren motsetter seg» (2). Det er imidlertid ingen lov som regulerer tvang og fastholding av barn innenfor pediatrisk omsorg $(3,4)$, men man kan si at tvang og makt forekommer når barnet motsetter seg behandling.

\section{Konsekvenser av tvang}

Tvang kan påføre barn psykiske, sosiale og utviklingsmessige belastninger. Fysiske skader har vært rapportert som følge av fysisk tvang, slik som ødemer og nerveskader etter at armer og/eller ben har vært bundet til sengen (5). Tvang kan gi fremtidig angst både generelt og for sykehus, og nedsatt evne til å danne tillitsfulle relasjoner. Det er også vist forsinket utvikling i språk og tale hos barn som har vært utsatt for tvang.

I sin ytterste konsekvens kan bruk av tvang også føre til dissosiative lidelser (6). Hvis barnet på et grunnleggende plan opplever å ikke være "god nok», hvor tanker og følelser ikke er integrert, eller hvor barnet ikke opplever seg som en trygg og «sammenhengende» person $(5,6)$ så kan det føre til dissosiative lidelser.

Det finnes ulike dimensjoner ved tvang som dekker ulike sider av tvangsfenomenet. For eksempel er det vanlig å dele inn tvangsmidler i tre kategorier; psykologisk tvang, tvang med bruk av medikamenter og fysisk tvang.

\section{Ulike former for tvang}

Kangasniemi og medarbeidere (4) fant at psykologisk tvang ble benyttet for å få barnet til å oppføre seg på en bestemt måte, det vil si ved hjelp av overtalelser, bestikkelser, utpressing eller fornærmelser på sykehuset. Vanligvis tok den psykologiske tvangen form av å måtte velge mellom to uønskede alternativer, men det kunne også være manipulering eller trusler.

Tvang med bruk av medikamenter betyr å gi beroligende medikamenter slik at barnet samarbeider bedre $(4,7)$.

Det finnes relativt lite i forskningslitteraturen om barns oppfatning av tvang. Fysisk tvang kan, i behandlingen av barn, være når en voksen holder barnet fast når det skal stikkes, eller at det benyttes ulike lakener eller binding. Dette kalles restriktive fysiske intervensjoner i litteraturen. I tillegg er isolasjon av barnet, i den hensikt å beskytte barnet mot infeksjoner, blitt regnet som tvang av noen forfattere.

Det finnes relativt lite i forskningslitteraturen om barns oppfatning av tvang. Det finnes noe mer litteratur om foreldres og helsepersonells oppfatninger om tvang (8). 


\section{Barns oppfatninger}

Det er få forskningsrapporter om førskolebarns reaksjoner, følelser eller oppfatninger ved bruk av tvang. Spesielt kan det være vanskelig å fange opp førskolebarns oppfatninger, da de er på et utviklingstrinn hvor deres evner til å danne seg en forståelse og fortolkning av verden ennå ikke er fullt utviklet. De reagerer mer direkte på det som hender dem. Bray og medarbeidere (9) konkluderte med at lite forskning på området er etisk svært uheldig fordi barnas perspektiv uteblir.

Oppsummert kan man si at en fortolkning av barns reaksjoner, uttrykk og atferd tyder på at bruk av tvang er vanskelig, utfordrende og overskrider deres mestringsevner i situasjonen.

Barns oppfatninger, reaksjoner og følelser relatert til situasjonen er derfor i de fleste forskningsrapporter gjort av foreldre, helsepersonell eller direkte av forskere som fortolker barnets uttrykk på vegne av barnet $(10,11)$. Dette fortolkningsarbeidet kan være utfordrende, fordi de som gjør fortolkningen også kan oppleve sterke emosjoner i situasjonen. Vi sitter dermed på svak evidens på hva som er barns selvopplevde oppfatninger.

\section{Forskjellige reaksjoner}

Forskningen som finnes viser at barnet kan reagere med protest, sinne og agitasjon mot helsepersonell og foreldre under behandling hvor tvang er involvert. Videre viser barna tegn på engstelse og redsel. Forskning har vist at mange barn har høye nivåer av stress og smerte (12-14).

Flukt, panikk og følelse av å miste kontrollen er også blitt identifisert $(10,13)$. I prosedyrerelaterte behandlingssituasjoner kan barn gjøre motstand i form av flukt, og de kan ha en følelse av å miste kontrollen over seg selv, samt oppleve resignasjon, overgivelse (14), skamfølelse og ydmykelse (12).

\section{Foreldres oppfatninger}

Forskning viser at foreldre utfører mye av tvangen i sykehus. Mange foreldre opplever slike situasjoner som traumatiske og utfordrende. En undersøkelse av fedre til barn med kreft oppga at de vurderte tvang som det mest utfordrende og følelsesmessige traumatiske aspekt ved barns sykehusopphold (15). Det er også funnet at noen foreldre blir irriterte og sinte fordi de opplever at behandlingen er lite individualisert, og at det er lite innlevelse og empati fra helsepersonell (7). Foreldrene opplever informasjonen som lite barnevennlig $(7,16)$. 
Mange foreldre mener at de har en uklar rolle i bruk av tvang og under medisinske prosedyrer. Forventningene som helsepersonell har til dem forblir usagt, og foreldrene kan dermed oppleve at de blir tatt for gitt i slike situasjoner (7). Det er også beskrevet hvordan mødre og fedre innlagt med langtidssyke barn ofte diskuterer og forhandler om hvem sin tur det er til å følge barnet til en smertefull behandling fordi ingen av dem vil være den som holder barnet fast $(17,18)$.

\section{Lite reell medvirkning}

Noen foreldre mener at tvang kan være nødvendig (19). Mange foreldre ønsker å være der for barnet i tvangssituasjoner. $\AA$ være der kan oppleves meningsfullt, noe som kan bety at de implisitt tolerer tvang fordi den bidrar til at barnet får behandling $(20,21)$. Foreldre har også etterlyst kompetanse og tekniske ferdigheter hos helsepersonell som kan bidra til at mislykkede prosedyreforsøk unngås og at dermed også tvang blir redusert (22).

Foreldre oppfatter at de har lite reell medvirkning i bruk av tvang.

Oppsummert kan man si at foreldre oppfatter at de har lite reell medvirkning i bruk av tvang: Det tilrettelegges i liten grad for oversikt og kontroll over situasjonen slik at foreldre makter å være et bindeledd mellom foreldre og sykehuset.

\section{Helsepersonells oppfatninger}

En del helsepersonell sier de ofte bruker tvang. Det fremkommer av litteraturen at det er uenighet blant helsepersonell om det å holde barn fast ved prosedyrer kan kalles tvang eller ikke $(4,22,23)$. Det er også ulike oppfatninger blant helsepersonell om hvor ofte tvang brukes (22). Sykepleiere og leger er ubekvemme når de snakker om tvang.

Helsepersonell vektlegger at de er skånsomme og bruker så lite makt eller kraft som mulig når de må holde barnet fast. Imidlertid tyder forskning på at helsepersonell mener at tvang kan være nødvendig, til tross for at det ikke er ønskelig, men at bruk av tvang ikke kan tas med i vurderingen av hvor nødvendig en behandling er eller ikke $(4,22,24,25)$.

Helsepersonell mener at bruk av tvang har uheldige konsekvenser fordi barnet blir stresset i tvangssituasjoner. Det kan bli vanskelig å gi god sykepleie til barnet hvis barnets tillit til personalet blir brutt $(14,19)$.

\section{Ikke-medikamentelle strategier}


Lloyd og medarbeidere hevder at sykepleiere kan oppleve bruk av tvang som emosjonelt stressende (25). Videre angir erfarne sykepleiere at de benytter tvang for å oppnå god praksis, slik at barnet får nødvendig behandling og for å lette arbeidet (4); for eksempel ved å binde barnets arm slik at barnet ikke plukker på det medisinske utstyret $(23,26)$.

Helsepersonell fremhever foreldrenes betydning og mener at trygge foreldre gir trygge barn, og utrygge foreldre gir utrygge barn. I situasjoner hvor foreldrene lar barna bestemme for mye er det også fare for bruk av tvang (22). Helsepersonells oppfatning viser også til betydningen av at foreldre vet hvor viktig prosedyren var for barnet slik at prosedyren kunne bli gjennomført (22).

Bruk av tvang er lite diskutert blant helsepersonell.

Sykepleiere som arbeider med barn har en oppfatning om at ikke-medikamentelle strategier som god informasjon, distraksjon, forutsigbarhet, samarbeid og tillitsfulle forhold kan bidra til å forhindre tvang (14). Når det gjelder medikamentelle strategier har bruk av bedøvelseskrem også vist seg nyttig for å samarbeide bedre med barnet $(14,22,27)$.

Oppsummert kan man si at helsepersonell har hovedfokuset på å levere medisinsk nødvendig helsehjelp, og at bruk av tvang er lite diskutert blant helsepersonell. Det er både delte oppfatninger om og lite faglig bevissthet rundt tvang. Tvang brukes derfor noen ganger som siste utvei og andre ganger som del av en mindre reflektert rutine.

\section{Ulike utfordringer}

Barnas, foreldrenes og helsepersonellets oppfatninger av tvang peker mot utfordringer på ulike plan. Utfordringene krever en sammensatt kompetanse for at helsepersonell skal gjennomføre behandling på en forsvarlig og omsorgsfull måte. Cowan og medarbeidere (28) ser på kompetanse som inkorporerer holdninger, verdier, kunnskap og ferdigheter hvor konteksten for praksisen inngår i forståelsen av kompetanse.

Kompetanseutfordring finnes i gapet mellom det som er den nødvendige kompetansen og den faktiske kompetansen hos helsepersonell. På bakgrunn av ovenstående kan det se ut til at det særlig er fire kompetanseutfordringer det bør reflekteres over: 1) Manglende bevissthet om bruk av tvang, 2) Manglende kunnskap om konsekvenser av tvang, 3) Lav grad av medvirkning, og 4) Lite fokus på strategier og tiltak som kan forhindre tvang. 


\section{Manglende bevissthet}

For å utvikle kompetanse som kan forhindre bruk av tvang er det først nødvendig å bli bevisst på at tvang brukes. For å svare på denne utfordringen må helsepersonell ikke bare bli bevisst på at tvang brukes, men også ta stilling til om den brukes på en planlagt og veloverveid måte. Det er kanskje ikke mulig å komme helt utenom tvang i medisinsk behandling av barn, men etiske diskusjoner på feltet anbefaler at det bør utvikles enighet om at bruk av tvang kun benyttes som siste utvei.

For å bidra til større bevissthet kan det være viktig at helsepersonell reflekterer over holdningene til bruk av tvang med kolleger. Dette innebærer at det må igangsettes jevnlige planlagte diskusjoner i miljøene slik at helsepersonell kan anerkjenne at noen barn kan oppleve handlingen som krenkende og ødeleggende. Dette krever at tvang anses som et faglig relevant problem og at minst mulig bruk av tvang blir ansett som en prioritet.

Erfaringer fra psykisk helsevern viser at utvikling av en slik type bevissthet er avhengig av langvarige forpliktelser og sterk lokal ledelse. Personalgruppen må involveres i gruppebaserte debrifinger av hver tvangssituasjon hvor hendelsesforløpet blir gjennomgått og analysert $(29,30)$.

\section{Trenger kunnskap om konsekvenser}

For å imøtekomme mangelen på kunnskap om konsekvenser av tvang er det viktig med faktabasert kunnskap som en del av et større undervisningsopplegg og trening av personalet som behandler barn. Det vil si om hvilke mulige alvorlige konsekvenser bruk av tvang kan ha på barnets fremtidige helse og utvikling. Inkludert i denne undervisningen kan det også være viktig å fremme og diskutere synet på barnet og elementer knyttet til barns utvikling.

Det er viktig å samtidig utvikle og spre kunnskap om alternativer til tvang. For å motvirke følelsen av håpløshet hos helsepersonell i møte med disse konsekvensene er det viktig å samtidig utvikle og spre kunnskap om alternativer til tvang. Å ta alvorligheten av konsekvenser av tvang inn over seg vil også forsterke bevissthet om bruk av tvang som adressert over.

\section{Lav grad av opplevd medvirkning}


En tredje kompetanseutfordring er at barn og foreldre oppfatter at de har lav grad av medvirkning i situasjoner der tvang anses som nødvendig. For å svare på denne utfordringen blir kunnskap om medvirkning og ulike nivåer av deltakelse grunnleggende. Forskning viser at det kan være nyttig å utvikle og implementere dialogbaserte modeller for medvirkning hvor relasjonsbygging, en klar plan for kommunikasjonsprosessen, tid og engasjement er sentrale faktorer. I en slik forståelse av medvirkning er engasjement, dialog mellom gruppene, fleksibilitet og respekt essensielt.

Helsepersonell må anerkjenne barns og foreldres perspektiv og meninger som unike og relevante og hvor målet er gjensidig forståelse for å oppnå større grad av medvirkning. Det betyr at kompetanseutviklingen må ta sikte på en dypere forståelse av medvirkning hvor man utforsker hva som skal til for at barn skal føle seg respektert i den aktuelle settingen.

Etisk refleksjon, lik vurdering av verdier og forståelse av grunnleggende begreper blir sentrale i kompetanseutviklingen. Viktige spørsmål er hvilke områder barnet kan medvirke til og hva reell medvirkning faktisk innebærer. Dette handler også om hvordan man ser på foreldre og barnet i pasient-/pårørenderollen. Blir barnet og foreldrene sett på som en passiv, lydig mottaker av behandling, eller som interaktive likeverdige deltakere? Dette kan kreve større strukturelle holdningsendringer på organisasjons-, gruppe- og individnivå (31).

\section{Lite fokus på strategier og tiltak}

Den siste kompetanseutfordringen dreier seg om manglende fokus på strategier og tiltak som kan forhindre tvang. Sentralt blir fokuset på hva som påvirker relasjonen til foreldre og barn, samt konkrete teknikker og intervensjoner som kan bidra til stressreduksjon, smertereduksjon og tillitsbygging. 
RÅD TIL HELSEPERSONELL: Forsøk å se det fra barnas perspektiv, anbefale... LES MER $\vee$ Et viktig innsatsområde er derfor å utvikle kompetanse på hvordan helsepersonell best kan trygge foreldre så mye som mulig foran og under en prosedyre. Dette kan innebære større medvirkning av foreldre, men også at det må utvikles bedre måter å forberede utrygge foreldre på. Dette kan for eksempel være å gi foreldrene verktøy som kan hjelpe barnet. Altså en utvikling av kontekstsensitive kunnskaper om metoder, verdier og holdninger som kan tilrettelegge for at foreldrene makter å formidle trygghet, og å være et bindeledd mellom barn og sykehus.

Videreutvikling og forsterkning av helsepersonells kunnskaper og ferdigheter i bruk av farmakologiske og ikke-farmakologiske intervensjoner kan bidra til å bedre situasjonen for barnet. Bedrede kommunikasjonsferdigheter og tekniske ferdigheter i gjennomføringen av en behandling bør også tillegges vekt i kompetanseutviklingen.

\section{Konklusjon}

Større bevissthet om bruk av tvang, tvangens potensielle ødeleggende virkninger, lav brukermedvirkning og manglende fokus på strategier og tiltak som kan forhindre tvang er sentrale kompetanseutfordringer.

Ansvaret for bruk av tvang må løftes opp som et felles anliggende.

Når helsepersonell befinner seg i en situasjon som allerede har eskalert i tvang, kan kanskje ingen kompetanse i verden forhindre bruk av tvang. Innsatsen må da muligens settes inn på forebygging av tvang, slik at foreldre og barn føler seg møtt og profesjonelt ivaretatt i ethvert møte med helsevesenet. Det enkelte helsepersonell som ikke ser andre alternativer enn tvang, fortjener støtte og tilrettelegging for å utvikle kompetanse. Ansvaret for bruk av tvang må derfor løftes opp som et felles anliggende i samfunnet og i organisasjonene.

\section{Referanser}

1. Crellin D, Babl FE, Sullivan TP, Cheng J, O'Sullivan R, Hutchinson A. Procedural restraint use in preverbal and early-verbal children. Pediatr Emerg Care. 2011;27(7):622-7.

2. Lov om kommunale helse- og omsorgstjenester m.m. (helse og omsorgstjenesteloven). Tilgjengelig fra: https://lovdata.no/dokument/NL/lov/2011-0624-30 (nedlastet 15.08.18)

3. Coyne I. Children's participation in consultations and decision-making at health service level: a review of the literature. Int J Nurs Stud. 2008;45 (11):1682 - 9. 
4. Kangasniemi M, Papinaho O, Korhonen A. Nurses' perceptions of the use of restraint in pediatric somatic care. Nurs Ethics. 2014;21(5):608-20.

5. Demir A. The use of physical restraints on children: practices and attitudes of paediatric nurses in Turkey. Int Nurs Rev. 2007;54(4):367-74.

6. Diseth TH. Dissociation following traumatic medical treatment procedures in childhood: A longitudinal follow-up. Dev Psychopathol. 2006;18(1):233-51.

7. Svendsen EJ, Moen A, Pedersen R, Bjørk IT. «But Perhaps they could Reduce the Suffering?» Parents' ambivalence toward participating in forced peripheral vein cannulation performed on their preschool-aged children. JPN: Nursing Care of Children and Families. 2018;41:46-51

8. Svendsen EJ, Moen A, Pedersen R, Bjork IT. Resistive expressions in preschool children during peripheral vein cannulation in hospitals: a qualitative explorative observational study. BMC Pediatr. 2015;15:190.

9. Bray L, Snodin J, Carter B. Holding and restraining children for clinical procedures within an acute care setting: an ethical consideration of the evidence. Nurs Inq. 2015;22(2):157-67.

10. Svendsen EJ, Moen A, Pedersen R, Bjork IT. Resistive expressions in preschool children during peripheral vein cannulation in hospitals: a qualitative explorative observational study. BMC Pediatr. 2015;15:190.

11. Harder M, Christensson K, Coyne I, Soderback M. Five-year-old children's tuningin and negotiation strategies in an immunization situation. Qual Health Res. 2011;21(6):818-29.

12. Karlsson K, Rydström I, Nyström M, Enskär K, Dalheim Englund A-C. Consequences of needle-related medical procedures: A hermeneutic study with young children (3-7 Years). JPN. 2016;31(2):109-18.

13. Lambrenos $\mathrm{K}$, McArthur E. Introducing a clinical holding policy. Paediatr Nurs. 2003;15(4):30-3.

14. Svendsen EJ, Bjørk IT. Experienced nurses' use of non-pharmacological approaches comprise more than relief from pain. J Pediatr Nurs. 2014;29(4):19-28.

15. McGrath $P$, Huff N. Including the fathers' perspective in holistic care. Part 2: Findings on the fathers' hospital experience including restraining the child patient for treatment. Aust J Holist Nurs. 2003;10(2):5-10.

16. Graham $\mathrm{P}$, Hardy M. The immobilisation and restraint of paediatric patients during plain film radiographic examinations. Radiography. 2004;10(1):23-31. 
17. Lam LW, Chang AM, Morrissey J. Parents' experiences of participation in the care of hospitalised children: a qualitative study. Int J Nurs Stud. 2006;43(5):535-45.

18. Swallow V, Lambert $H$, Santacroce $S$, Macfadyen A. Fathers and mothers developing skills in managing children's long-term medical conditions: how do their qualitative accounts compare? Child Care Health Dev. 2011;37(4):512-23.

19. Berglund IG, Ericsson E, Proczkowska-Björklund M, Fridlund B. Nurse anaesthetists' experiences with pre-operative anxiety. Nurs Child Young People. 2013;25(1):28-34.

20. Sparks LA, Setlik J, Luhman J. Parental holding and positioning to decrease IV distress in young children: a randomized controlled trial. J Pediatr Nurs. 2007;22(6):440-7.

21. McGrath $P$, Forrester $K$, Fox-Young $S$, Huff N. «Holding the child down» for treatment in paediatric haematology: the ethical, legal and practice implications. J Law Med. 2002;10(1):84-96.

22. Svendsen EJ, Pedersen R, Moen A, Bjork IT. Exploring perspectives on restraint during medical procedures in paediatric care: a qualitative interview study with nurses and physicians. Int J Qual Stud Health Well-being. 2017;12(1):1363623.

23. Kirwan L, Coyne I. Use of restraint with hospitalized children: A survey of nurses' perceptions of practices. J Child Health Care. 2016.

24. Bricher G. Paediatric nurses, children and the development of trust. J Clin Nurs. 1999;8(4):451-8.

25. Lloyd M, Law GU, Heard A, Kroese B. When a child says 'no': experiences of nurses working with children having invasive procedures. Paediatr Nurs. 2008;20(4):29-34.

26. Homer JR, Bass S. Physically restraining children for induction of general anesthesia: Survey of consultant pediatric anesthetists. Paediatr Anaesth. 2010;20(7):638-46.

27. Berglund M, Westin L, Svanstrom R, Sundler AJ. Suffering caused by carepatients' experiences from hospital settings. International journal of qualitative studies on health and well-being. 2012;7:1-9.

28. Cowan DT, Norman I, Coopamah VP. Competence in nursing practice: a controversial concept-a focused review of literature. Nurse Educ Today. 2005;25(5):355-62. 
29. Scanlan JN. Interventions to reduce the use of seclusion and restraint in inpatient psychiatric settings: what we know so far a review of the literature. Int J Soc Psychiatry. 2010;56(4):412-23.

30. Boumans CE, Walvoort SJ, Egger JI, Hutschemaekers GJ. The methodical work approach and the reduction in the use of seclusion: how did it work? Psychiatr Q. 2015;86(1):1-17.

31. Coyne I. Children's participation in consultations and decision-making at health service level: A review of the literature. Int J Nurs Stud. 2008;45 (11):1682-9.

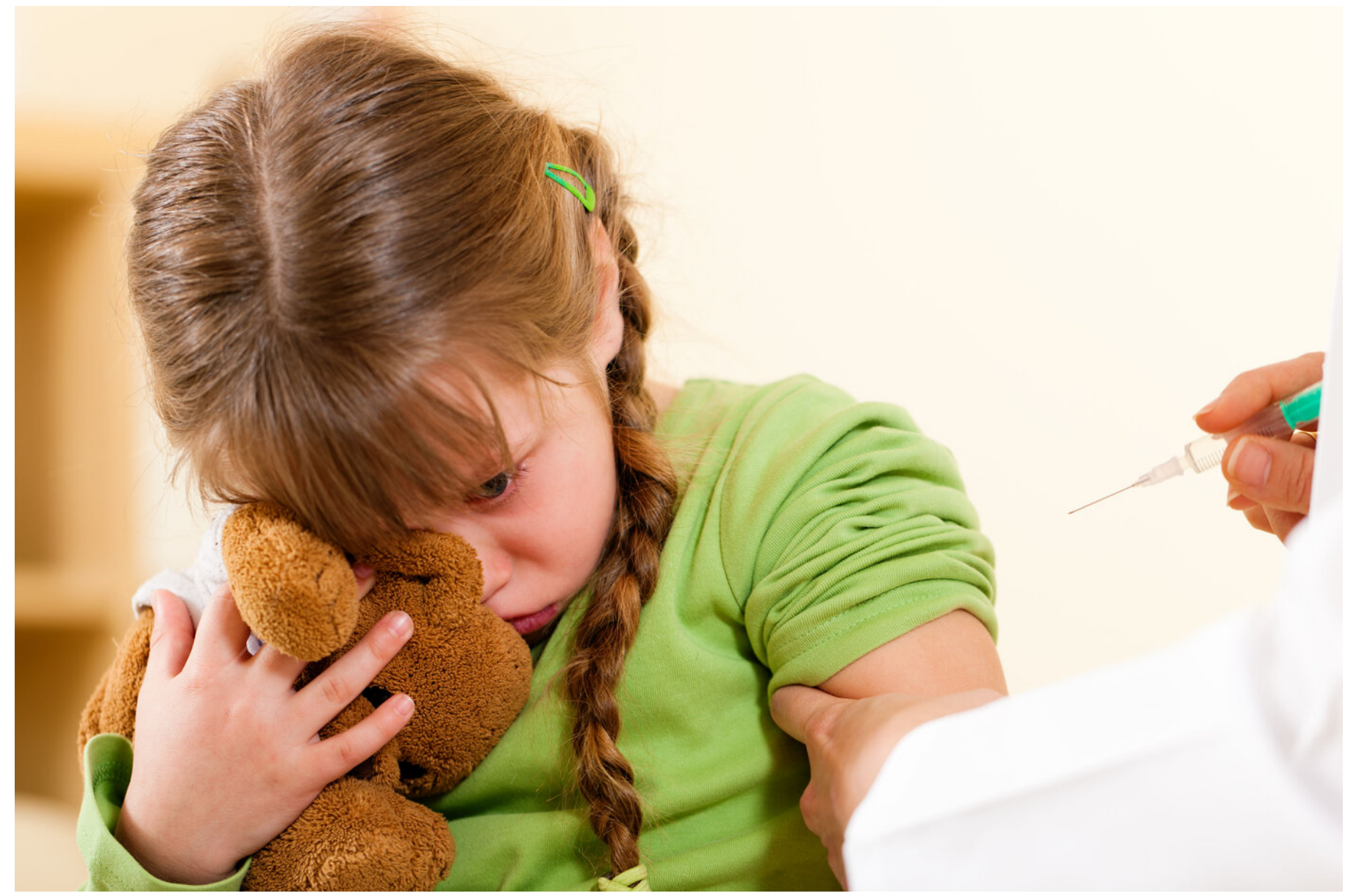

KAN FÅ KONSEKVENSER: Tvang kan påføre barn både psykiske, sosiale og... LES MER $\vee$ 